\title{
INTELLEKTUAALSEID VÕIMEID TÄHISTAVATE SÕNADE KASUTUSED INTELLEKTUAALSES TEGEVUSES EESTI KEELE MAAILMAPILDIS
}

\section{Larissa Degel}

\begin{abstract}
Ülevaade. Artiklis uuritakse mõtlemise, mõistmise ja mäluga seotud intellektuaalsete võimete rolle eesti keele maailmapildis. Uurimisobjektiks on intellektuaalseid võimeid tähistavad sõnad eesti keeles: aju(d), ajukäärud, aru, hallollus, intellekt, meel, mõistus, pea, taip, teadvus. Uurimuse eesmärk on tabada sõnakasutuses peituvaid "naiivseid" ettekujutusi inimese intellektist. Uurimismaterjal pärineb Tartu Ülikooli kirjakeele korpusest, otsingumootorist Google, kasutatud on ka "Eesti kirjakeele seletussõnaraamatut”. Intellektuaalsed protsessid ja seisundid eesti keele maailmapildis esitatakse kontseptuaalsete metafooride kujul. Ehitatakse üles mõtlemise, mõistmise ja mälu metafoore.
\end{abstract}

Võtmesõnad: mentaalne maailmapilt, intellektuaalsfäär, naiivteooria, kontseptuaalsed metafoorid, eesti keel

\section{Keel, mida me kasutame}

Naiivteooriad - tavainimeste maailmavaatelised teadmised, arusaamad, ettekujutused materiaalse maailma nähtustest ja objektidest ning mittemateriaalsetest psüühilistest struktuuridest ja protsessidest - peituvad keele grammatikas, süntaksis, sõnavaras, sõnade tähendustes ja kasutustes. Keelt kasutades ei pane me tähelegi, et eri konstruktsioonidesse on kompaktselt ja kõnelejale nähtamatult "pakitud" maailmavaatelisi teadmisi, konnotatsioone, assotsiatsioone, tähendusvarjundeid. Keelelise maailmapildi teooria järgi näevad, mõistavad, tunnetavad eri keelte kõnelejad maailma pisut erinevalt, omamoodi - läbi oma emakeele prisma. Siinses artiklis käsitletakse intellektuaalset tegevust intellektuaalseid võimeid tähistavate sõnade kasutuste põhjal. Sõnakasutused näitavad, missugused on intellektuaalsed võimed eesti keele maailmapildis, milline on intellektuaalsete võimete roll intellektuaalses tegevuses ning kuidas kulgevad protsessid ja seisundid eesti keele maailmapildi intellektuaalsfääris. 


\subsection{Uurimuse eesmärk}

Seni ilmunud intellektuaalsfääri uurimustes on tähelepanu keskmes olnud eeskätt sõnavara ning intellektuaalsfääri protsessid ja seisundid (D’Andrade 1987, D’Andrade 1995, Apresjan 1995, Fortescue 2001), kuid varju on jäänud intellektuaalsed võimed, nende rollid intellektuaalsfääri protsessides ja seisundites, viisid, kuidas need protsessid ja seisundid kulgevad intellektuaalsfääri sees. Intellektuaalsfääri uurijatest on intellektuaalse tegevuse metafoore seni püüdnud käsitleda ainult Olaf Jäkel (1995), kelle inglise keele andmete põhjal üles ehitatud mudeli (ingl Mental activity is manipulation) moodustavad mõtted (ideas), mind kui teadlikkus (mind-consciousness) ja mind kui intellekt (mind-intellect), mälu (memory), teadmised (knowledge), probleemid (problems) ja lahendused (solutions) ning tegevused, nagu mõistmine (understanding), probleemi lahendamine (solving a problem), mentaalne uurimine (mental investigation), mõtete väljakujunemine (forming ideas), otsustamine, arutlemine (judging), meenutamine, meenumine (memorizing, remembering), meelespidamine (keep in memory), unustamine, ununemine (abandoning ideas). Mudel esitab mentaalset tegevust kui inimese poolt sooritatavat objektide käsitsemist (physical manipulation of solid objects), mille puhul intellektuaalsed võimed täidavad instrumendi rolli (the mind is a tool) või esinevad töökojana (the mind is a workshop).

Intellektuaalsete võimete olemasolust sõltub, kas inimene on tark või rumal. Kui inimesel on intellektuaalne võime olemas (inimene on nt peaga, ajudega, aruga või inimesel on mõistust, nutti), siis on inimene tark, arukas. Kui inimesel intellektuaalset võimet pole (nt pole aru peas, inimene on mõistuseta, ajudeta), siis on ta rumal. Intellektuaalsed võimed osalevad intellektuaalsetes protsessides ja seisundites.

Käesoleva uurimuse eesmärk on uurida mõtlemise, mõistmise ja mäluga seotud intellektuaalsete võimete rolle eesti keele maailmapildis. Kas eesti keele maailmapildis piirduvad rollid instrumendiga ja töökojaga (nagu äsjamainitud Jäkelil)?

\subsection{Uurimisobjekt, -materjal, -meetod}

Uurimisobjektiks on intellektuaalseid võimeid tähistavate sõnade ( $a j u(d)$, ajukäärud, aru, hallollus, intellekt, meel, mõistus, pea, taip, teadvus) ${ }^{1}$ kasutused intellektuaalse võime tõlgenduses. Rolli määratlemisel keskendusin lauses rakendatud metafoorile. Analüüsitud sõnakasutuste põhjal ehitasin üles intellektuaalsete võimete rollide, intellektuaalsete protsesside või seisundite kontseptuaalsed metafoorid, mis süsteemsetes kognitiivsetes projektsioonides peegelduvad konkreetselt abstraktsele.

Nagu kõigest muust, mida pole võimalik silmaga näha või käega katsuda, räägime ka intellektuaalsetest protsessidest ja seisunditest metafooride abil: "It is virtually impossible to think or talk about the mind in any serious way without conceptualizing it metaforically" (Lakoff, Johnson 1999: 235). Mõtlemise, mõistmise, mälu protsesside ja seisundite esitamisel ehitatakse metafoor üles järk-järgult (ülevalt alla) ning kõigi komponentide kaupa.

Põhimaterjal pärineb eesti kirjakeele korpusest ja eestikeelsest otsingumootorist Google (kogutud ajavahemikul oktoober 2006 kuni aprill 2007). Kasutatud on 
ka "Eesti kirjakeele seletussõnaraamatu" (edaspidi EKSS) näitelauseid. Analüüsitud on materjali kogu oma mitmekesisuses: ilukirjanduslikest tekstidest netikommentaarideni, eeskätt tänapäeva keelekasutust. Materjali kogumisel ja analüüsil olen püüdnud hõlmata nii palju kättesaadavat materjali kui võimalik, jättes siiski kõrvale kasutused, mille puhul on Google'is esinenud ainult üks kontekst, s.t mis on vaadeldavas tähenduses ja vormistuses esinenud ainult üks kord. Iga uuritava sõna puhul on vaadeldud selle kõiki muutevorme.

\section{Intellektuaalsfääri sisu}

Intellektuaalse tegevuse ja intellektuaalsete võimete rollide metafooride ülesehitamisel rakendatakse käesolevas artiklis koondkategooriat INFORMATSIOON, mis on metafooride konstrueerimise lähtepunkt. INFORMATSIOON hõlmab intellektuaalsfääri täitvat sisu kogu oma mitmekesisuses. INFORMATSIOON esineb keelelises maailmapildis ainena:

\section{INFORMATSIOON ON AINE}

Ainena esineval INFORMATSIOONIL on palju erinevaid ilmeid ja nimesid: INFORMATSIOON võib esineda mõtete, ideede, ootuste, lootuste, soovide, veendumuste, arvamuste, hinnangute, oletuste, unistuste, plaanide, kiindumuste, murede, probleemide, mälestuste, teadmiste vms nime all (1). INFORMATSIOONI moodustavad mittemateriaalsed, abstraktsed ideed, probleemid, mõtted jms "esemestuvad" keelelises maailmapildis: INFORMATSIOON võtab objektide või nähtuste kuju, täidab mahutit, nagu seda teevad esemed, füüsilised objektid (2).

(1) Loomulikult on nad esimesed võimalused, mis pähe tulevad. (SEGAILU/0004)

(2) --- "Sel ajal olin mina kaheksateistkümneaastane noor poiss, pea täis plikasid ja mässuvõitlust.” (SEGAILU/o024)

George Lakoffi ja Mark Johnsoni (1980: 25) terminoloogias on "esemestumise" puhul tegu nn ontoloogilise metafooriga, mis lubab rääkida abstraktsetest mõistetest ja mittemateriaalsetest nähtustest konkreetsete, füüsiliste objektide kaudu. Lakoffi ja Johnsoni (1999: 235-241) Embodied Mind'i metafoorides esinevad mõtted olenevalt käsitletavast fragmendist kui füüsilised objektid (metafooris The Mind as Body System, kus mõtlemine on füüsilise keha funktsioneerimine), asukohad (metafooris Thinking is Moving, kus mõtlemine on liikumine), vastuvõetavad, tajutavad asjad, objektid (metafooris Thinking is Perceiving, kus mõtlemine on vastuvõtmine), käsitsetavad objektid (metafooris Thinking is Object Manipulation, kus mõtlemine on objektide käsitsemine), toit (metafooris Acquiring Ideas is Eating, kus mõtete omandamine on söömine). Mudeli Mental activity is manipulation üks esimesi ja põhjapanevaid komponente on metafoor Ideas are solid objects. Toetudes ingliskeelsele materjalile, näitab Jäkel (1995: 199), et mõtted omavad keeles tahkete füüsiliste objektide kõiki olulisi omadusi: mõte on mitmemõõtmeline, mõtete keerulisus esineb kui kõvadus või sitkus, mõtete tähtsus esineb kui füüsiline kaal, mõtteid ja teadmist esitatakse kui väärisesemeid. 


\subsection{Intellektuaalsed võimed INFORMATSIOONı mahutina}

Intellektuaalsete võimete üks võimalikest rollidest on INFORMATSIOONI mahuti. Mahuti võib olla INFORMATSIOONIGA täidetud või INFORMATSIOONIST tühi. INFORMATSIOON läbib mahutis kolm etappi: ilmub mahutisse, viibib mahutis, lahkub mahutist. INFORMATSIOONI ilmumine, viibimine, lahkumine on üks võimalikke viise, kuidas keel esitab intellektuaalseid protsesse ja seisundeid:

\section{INFORMATSIOON ON AINE \\ INTELLEKTUAALNE VÕIME ON MAHUTI, KUS PAIKNEB AINE}

INFORMATSIOON ilmub mahutisse kolmel erineval moel: tekib mahuti sees, väljendades oma esmakordset esiletulekut (3), siseneb mahutisse väljastpoolt (4) või seda sisestatakse mahutisse (5). Mahutis viibivat INFORMATsIOONI iseloomustab kaksipidine käitumine - aktiivne ja passiivne. Aktiivne käitumine esineb eeskätt liikumisena (6), passiivne olek on mahutis hoiul viibimine (7). INFORMATSIOON võib inimese tahtest olenemata mahutist lahkuda (8).

(3) --- minu peas sündis kujutlus veiniteatmikust, milline meil võiks leiduda. (Google; www.blog.ekspress.ee)

(4) Esimese mõttena torkas mõistusesse, et tegu on liiklusummikuga --(Google; jah.pri.ee)

(5) Bussisõidu ajal kipuvad vägisi pähe tulema kunagi ajju topitud teadmised komparteist --- (Postimees_Extra_200o)

(6) Eks sellepärast enesetapukatsed poomise läbi nii kergesti korda lähegi, jookseb mõte läbi aju. (SEGAILU/OO12)

(7) Ametnik, kellel maaseadus peas, dikteeris Mikale ---. (ILU1990/ iluoo78)

(8) Ta oli viivuks sellele mõelnud, kuid siis lendas kõik peast ... kuni oli Aidanni külatüdruku seltsis puude vahel näinud. (SEGAILU/0107)

\subsection{Intellektuaalsed võimed instrumendina}

Intellektuaalne tegevus võib esineda keelelises maailmapildis kui intellektuaalsete võimete inimesepoolne kasutamine instrumendi või ruumina. Inimene kasutab intellektuaalseid võimeid instrumendina (9-10), et midagi saavutada või mingit tegevust sooritada:

INTELLEKTUAALNE VÕIME ON INSTRUMENT

INTELLEKTUAALNE TEGEVUS ON INSTRUMENDI INIMESEPOOLNE KASUTAMINE

(9) See küsimus ongi selleks välja mõeldud, et inimene oma hallollust kasutaks. (Google; www.baka.ee)

(10) Hakkab peaga ${ }^{2}$ leiba teenima. (EKSS)

2 Eesti keele komitatiiv võib esineda nii kaaslase kui ka vahendina, millele juhib tähelepanu Helle Metslang (2002: 166-167). Näites (10) esineb intellektuaalseid võimeid tähistav sõna komitatiivis, mis toimib instrumentaali funktsioonis, märgib vahendit. 
Kasutades intellektuaalseid võimeid instrumendina, sooritab inimene nii mentaalsesse maailmapilti mahtuvaid tegevusi kui ka tegevusi, mis ei kuulu mentaalsesse maailmapilti, nt tegevusi, mille eesmärgiks on materiaalse heaolu saavutamine, materiaalsete hüvede teenimine ja nende suurendamine:

(11) Neljapäeval, 5. juunil, peaks sul olema võimalik mõistuse abil oma varandust suurendada ---. (Eesti_Ekspress_1997)

\title{
2.3. Intellektuaalsed võimed ruumina
}

Inimene võib kasutada intellektuaalseid võimeid ka ruumina, kus ta sooritab tegevust:

\author{
INTELLEKTUAALNE VÕIME ON RUUM \\ INTELLEKTUAALNE TEGEVUS ON INIMESE TEGUTSEMINE RUUMI SEES
}

Teen põhimõttelist vahet intellektuaalsete võimete mahutina esinemise ja ruumina kasutamise vahel. See on tingitud intellektuaalsete võimete eristuvatest rollidest: mahutis paikneb INFORMATSIOON, samas kui intellektuaalset tegevust sooritav inimene viibib intellektuaalsetes võimetes kui ruumis. Jäkel (1995: 217) käsitleb intellektuaalseid võimeid selles rollis töökojana (The mind is a workshop), kus ideed on sätitud riiulitesse vastavalt nende tähtsusele, jättes seega tähelepanuta töökoja sees toimuva tegevuse. Siin artiklis kasutan Jäkeli (1995) mental workshop’i vastena ruumi (mitte mahutit).

Intellektuaalsetes võimetes ruumina võib inimene tajuda, nt näha (12) ja kuulda (13). Intellektuaalsetes võimetes ruumina võib inimene sooritada arvutamist (14).

(12) --- mida ma oma peas näen on kusagil ka tõepoolest olemas ja mingil isemoodi moel olen ma seal ka käinud --- (Google; foorum.keskmaa.ee)

(13) Vahel kuulen peas suurepärast muusikat, kuid ei suuda seda paberile panna. (Google; www.poogen.ee)

(14) Millegipärast jõuab laev Paldiskisse tunduvalt varem, kui oma peas olin arvutanud. (Eesti_Ekspress_2001)

\subsection{Intellektuaalsed võimed tegijana}

Intellektuaalsed võimed võivad eesti keele maailmapildis esineda tegijana ja sooritada tegevust:

\section{INTELLEKTUAALNE VÕIME ON TEGIJA \\ INTELLEKTUAALNE TEGEVUS ON TEGIJA TEGUTSEMINE}

Erinevalt instrumendi rollist (mis hõlmas nii mentaalset kui ka mittementaalset maailmapilti), sooritavad intellektuaalsed võimed tegijana ainult mentaalse maailmapildi tegevusi: nii neid, mis kuuluvad intellektuaalsfääri (15), kui ka neid, mis 
hõlmavad emotsioone ja tundeid (16), soove (17), kõnet (18), nt intellektuaalne võime võib tunda, tahta või rääkida.

(15) Kui meie mõistus mõistab elu valesti, siis keha kannatab. (Google; www.luuleviilma.ee)

(16) Inimese mõistus tunneb ennast koduselt ainult siis, kui ta saab pidevalt avastada väikesi ebatäiuslikkusi, ebakorrapära, ebaloogilisust jne. (Google; www.postimees)

(17) Mõistus tahab ise areneda, andke talle see võimalus ja ta vastab teile tänulikkusega. (Google; www.aasiareisid.ee)

(18) --- aga minu aru ütleb, et kui kogu su tegevuse ja olemise aluseks on vabadus ---. (Google; www.newflow.ee)

\title{
3. Intellektuaalsete võimete rollid mõtlemisel
}

Mõtlemine esineb eesti keele maailmapildis nii mahuti sees toimuva, kui ka inimese poolt või intellektuaalsete võimete poolt sooritatava protsessina. Mahuti sees kulgevat mõtlemist mõistetakse kas liikumise, töö(tlemise) või muut(u)misena, kusjuures kõigil juhtudel kehtib metafoor INFORMATSIOON ON AINE. Mõtlemisel-liikumisel toimub mahutis liikumine, nii et kontseptuaalse metafoori võib sõnastada järgmiselt:

\author{
INFORMATSIOON ON AINE \\ INTELLEKTUAALNE VÕIME ON MAHUTI \\ MÕTLEMINE ON AINE LIIKUMINE MAHUTI SEES
}

Mõtlemine esineb keelelises maailmapildis kui inimesest osaliselt sõltumatu ja osaliselt sõltuv. Inimesepoolset kontrolli väljendab INFORMATsıoONI liikumise käivitamine (19-20) või INFORMATSIOONI keerutamine (21).

(19) Sain kinnitust paljudele asjadele, mida olin varem oma peast läbi lasknud. (Eesti_Ekspress_1997)

(20) --- ma ei lase seda teadvusest läbi, aga ma tahan nendega tuttavaks saada, sinna sisse saada. (Eesti_Ekspress_1999)

(21) Keerutan peas ka romaanifragmente. (Eesti_Ekspress_1998)

INFORMATSIOON liigub mahuti sees erineva kiiruse ja intensiivsusega. Hoogsat, palavikulist, kiiret mõtlemist kirjeldab INFORMATSIOONI kiirem liikumine - lippamine (22), jooksmine (23), tormlemine (24).

(22) Leena tundis, et mõtted lippavad nii kiiresti läbi pea, et ta ei jõua mitte ühtegi neist lõpuni mõelda. (SEGAILU\ooo8)

(23) Eks sellepärast enesetapukatsed poomise läbi nii kergesti korda lähegi, jookseb mõte läbi aju. (SEGAILU \0012)

(24) Väliselt ei öelnud miski mulle, et peale ajukäärudes tormlevate ideede võiks --- mehel veel midagi hirmväärtuslikku üle ääre pulbitseda. (Google; arhiiv2.postimees.ee8080) 
Intensiivne mõtlemine esineb INFORMATSIOONI keerlemise (25), tiirutamise (26), pöörlemisena (27) mahutis. Peale ringlemise võib mõtlemise intensiivsust edastada INFORMATSIOONI monotoonne edasi-tagasi liikumine, tagumine (28), millega kaasneb (tajutav, kuuldav) kloppimine, vasardamine (29), tuksumine, põksumine, trummeldamine (30). Vähem intensiivset mõtlemist iseloomustab INFORMATSIOONI aeglasem, sujuvam ja voolavam liikumine (31-33).

(25) Kõik see, mida ta selle maailma kohta teada saada jõudnud oli, hakkas ta teadvuses keerlema, ja peagi ei jaksanud ta enam isegi muusikat kuulata. (SEGAILU \0004)

(26) peas aga tiirutab homne Tallinna-sõit või mõni päevauudistes kuuldud teade. (ILU1990 \iluo246)

(27) Keegi ei wastanud temale enam, igaühe ajus pöörles pime, raske mõte, küßimus, et miks on elus nii palju waewa, wiletßußt, nälga? (ILU1910 \ iluoo77)

(28) “Välja siit!” taob kinnismõte läbi pea. (ILU1990\iluo015)

(29) Miks just mina, vasardab mõne tubli pereisa ajus, kes on kolme õlle pärast autoroolist maha võetud ja ränga trahvi saanud. (Google; vabaeuroopa.org)

(30) --- nüüd trummeldab hallolluses pidevalt üks asi - seks, seks, seks (Google; www.ohtuleht.ee)

(31) Sellised küsimused sõlmuvad üksikisiku meeles ---. (Eesti_Ekspress_1999)

(32) --- vaataja teadvuses heljuvad kujundid siiski peidavad eneses satori, flashi võimalust ---. (Google; www.postimees.ee)

(33) Tema peas uitab ainult üks mõte - tahaks venda juba näha, nii palju on aega. (Google)

Informatsioon ei pruugi liikuda ainult kindlas suunas (edasi, edasi-tagasi, ringi, läbi või mööda). Kiiret, palavikulist mõtlemist iseloomustab korrapäratus - informatsiooni liikumine võib muutuda kaootiliseks (34), käia korraga mitmes erinevas suunas (35), seguneda (36).

(34) Sõnad ja mõtted keerlevad - tiirlevad - joonduvad - liuglevad tema peas nagu purjus baleriinid (Google; www.poogen.ee)

(35) Need küsimused ristlesid ajus. (ILU1930\ramooo7)

(36) Läbielatu, muljed ja mälestused segunesid mu ajus üheks suureks seikluseks ---. (SEGAILU\0007)

INFORMATSIOON ei pruugi elada aktiivset elu, liikuda ja muutuda, ta võib viibida mahutis staatilises olekus. Staatilisus avaldub kahtepidi: kui seismine/istumine ja kui hoiul olek. INFORMATSIOONI seismine/istumine väljendab mõtlemist - võib oletada, et see on mõtlemise kui INFORMATSIOONı liikumise seiskumine. Seiskumine väljendab 
mõtlemise intensiivsust, pidevat, lakkamatut mõtlemist, keskendumist ainult ühele mõttele (37). INFORMATSIOONI mahutis hoiul olek väljendab mäletamist.

(37) Kui isegi satun korraks lugema, istub peas mõte, et jää vait ja kasva suureks ning saa üle juba. (Google: www.parnupostimees.ee)

Peale liikumise võib INFORMATSIOONI aktiivsus avalduda muut(u)misena - mahutis viibides võib INFORMATSIOON (välja) kujuneda (38), valmida (39), küpseda (40) või INFORMATSIOONI võib arendada (41), küpsetada (42). INFORMATSIOON muutub ainult väljakujunemise, arenemise suunas (INFORMATSIOON ei lagune ära ega hävine, vaid areneb, küpseb, valmib). INFORMATSIOONI muutmine on võimalik samuti ainult arendamise, küpsetamise suunas.

\author{
INFORMATSIOON ON AINE \\ INTELLEKTUAALNE VÕIME ON MAHUTI \\ MÕTLEMINE ON AINE MUUT(U)MINE MAHUTIS
}

(38) Pikapeale kujunes tema teadvuses kolooniagi mingiks suhtelise vabaduse ja iseseisvuse võrdkujuks, kui koduga kõrvutada. (ILU1970 \iluo028)

(39) Minu loengud valmivad mu peas. (Postimees_1997)

(40) --- tegelikult küpses prügikorjamise idee tema ajus juba ammu. (Eesti Ekspress_2000)

(41) Seda mõtet arendades sünnib Theodori peas siiski Vabadussõja-ainelise "Noorte kotkaste" idee. (Postimees_1996)

(42) Enamasti küpsetab fotograaf ideed oma peas nädalaid või kuidki. (Eesti_Ekspress_2001)

Mõtlemine võib esineda ka inimese poolt sooritatava tegevusena. Kui mõtlemist sooritab inimene, siis kasutab ta intellektuaalseid võimeid kas instrumendi või ruumina. Jäkel (1995: 206) esitab mõtlemist metafoorina Thinking is working on problem objects with the mind tool. Lausetes (43-44) esineb mõtlemine inimese poolt sooritatava tegevusena, mille puhul intellektuaalseid võimeid rakendatakse tööle instrumendina.

(43) --- S. mõtle aruga ma saan aru et ta sulle meeldib --- (Google: www. lapsemure.ee)

(44) Narkoennetuspäev ärgitas noori oma peaga mõtlema (Google; www. valgamaalane.ee)

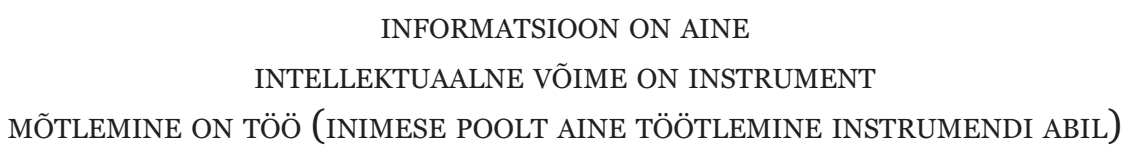

INFORMATSIOON ON AINE

INTELLEKTUAALNE VÕIME ON INSTRUMENT

MÕTLEMINE ON TÖÖ (INIMESE POOLT AINE TÖÖTLEMINE INSTRUMENDI ABIL)

Inimene võib kasutada intellektuaalseid võimeid ka ruumina, s.t mõtlemise sooritamise asukohana:

(45) Mõtlen oma peas igasuguseid asju välja, et Ta saaks jälle öelda, et ma rahuneksin. (Google; blog.delfi.ee) 


$$
\begin{gathered}
\text { INFORMATSIOON ON AINE } \\
\text { INTELLEKTUAALNE VÕIME ON RUUM } \\
\text { MÕTLEMINE ON TÖÖ (INIMESE POOLT AINE TÖÖTLEMINE RUUMIS) }
\end{gathered}
$$

Intellektuaalsed võimed võivad sooritada mõtlemist ise, tegijana:

(46) Tema aju töötas mitmete erinevate päästmisplaanide kallal: kas pakkuda töölistele raha, et nad kuju maha ei tõmbaks? (SEGAILU/o024)

\author{
INFORMATSIOON ON AINE \\ INTELLEKTUAALNE VÕIME ON TEGIJA \\ MÕTLEMINE ON TÖÖ (TEGIJA POOLT AINE TÖÖTLEMINE)
}

D’Andrade (1987: 135) kirjeldab mõtlemist kui mõtetest mõtete tootmist: “Thoughts are related to each other. Sometimes, one thought leads to another; sometimes one recognizes inconsistency between thoughts; sometimes one can figure out something from other things one knows or believes". Mõtlemine võib ka eesti keeles esineda intellektuaalsete võimete poolt sooritatava INFORMATSIOONI tootmise (47), loomise (48), konstrueerimisena (49).

(47) No see on muidugi eriti äärmuslik kriisisituatsioon, mille minu pisut väärastunud mõistus tootis, aga loodan, et keegi veel saab aru, mida ma silmas pidasin (Google; juulik.wordpress.com)

(48) Märkan äkilise selgusega, et mõistus, intellekt, loob omad probleemid ja teeb seejärel olemise viletsaks, üritades neid lahendada. (Google; teofilosoofia.ee)

(49) Tema loominguline aju hakkas kohe konstrueerima oletusi uue teksti kohta ---. (SEGAILU \0115)

INFORMATSIOON ON AINE

INTELLEKTUAALNE VÕIME ON TEGIJA

MÕTLEMINE ON AINE TOOTMINE TEGIJA POOLT

\title{
4. Intellektuaalsete võimete rollid mõistmisel
}

Mõistmine esineb keelelises maailmapildis põhiliselt INFORMATSIOONIGA läheduse saavutamisena. Jäkeli (1995: 199-205) üles ehitatud mudelis Mental activity is manipulation koosneb metafoor Understanding an idea is establishing physical closeness neljast komponendist: mõtleja otsib mentaalse vahemaa vähendamise võimalusi, haarab mõttest kinni, võtab selle maast üles, paneb mahutisse.

\section{INFORMATSIOON ON AINE \\ MÕISTMINE ON AINEGA LÄHEDUSE SAAVUTAMINE}

Eesti keele maailmapildis on võimalik nii inimese või intellektuaalsete võimete aktiivne tegutsemine kui ka INFORMATSIOONI enese jõudmine mahutini/mahutisse. Lause (50) esitab mõistmist INFORMATSIOON jõudmisena mahutisse, lause (51) jõudmisena mahutini. INFORMATSIOONI jõudmist mahutisse võib takistada INFORMATSIOONI 
sisu - absurdse (52), imeliku, kummalise (53) sisuga INFORMATsioon ei mahu mahutisse.

(50) “Loodetavasti jõuab nüüd ka vägivallatsejate ajudesse, millist häbi nad oma käitumisega Inglismaale on teinud," (Postimees_2000)

(51) Et ka vanus enamikust mööda ei lähe, pole jõudnud veel ajukäärudeni. (Postimees_1998)

(52) Mul ei mahu see pähe, kuidas saab neljakümne häälega pääseda linna volikogusse. (AJAE1990 \stako233)

(53) Punk on midagi kummalist, mis lihtkodaniku ajudesse ei mahu. (Google; vooremaa2001.tripod.com)

\author{
INFORMATSIOON ON AINE \\ INTELLEKTUAALNE VÕIME ON MAHUTI \\ MÕISTMINE ON AINE JÕUDMINE MAHUTISSE/MAHUTINI
}

Mõistmine esineb eesti keele maailmapildis intellektuaalsete võimete poolt sooritatava INFORMATSIOONI vastuvõtmisena (54). Suutmatus seda vastu võtta on suutmatus mõista (55).

(54) Omandab innukalt kõike, mida ta taip suudab vastu võtta. (EKSS)

（55） K.-i meel ei võta vastu teadmist, et tema majapidamises talitas mees, kelle kohus võib tunnistada Eesti ajaloo julmimaks sarimõrvariks (Google; www.ohtuleht.ee)

\author{
INFORMATSIOON ON AINE \\ INTELLEKTUAALNE VÕIME ON TEGIJA \\ MÕISTMINE ON AINE VASTUVÕTMINE TEGIJA POOLT
}

Mõistmine võib esineda eesti keeles ka inimese poolt sooritatava INFORMATSIOONI haaramisena, mille puhul intellektuaalseid võimeid rakendatakse instrumendina:

(56) Venemaa kohta on tavaks öelda, et seda maad ja rahvast pole võimalik mõistusega haarata, teda saab uskuda või karta. (Google; www.riigikogu.ee)

\author{
INFORMATSIOON ON AINE \\ INTELLEKTUAALNE VÕIME ON INSTRUMENT \\ MÕISTMINE ON AINE INIMESE POOLT HAARAMINE INSTRUMENDI ABIL
}

Mõistmist (kinni)võtmise, (kinni)haaramise kujul esitav metafoor Understanding is seizing idea objects firmly on üks komponentidest mudelis Mental activity is manipulation (Jäkel 1995: 202). Vakk (1970: 31) juhib tähelepanu sellele, et paljudes indoeuroopa keeltes tuntakse mõistmist väljendavaid verbe, mis algselt tähendasid just (kinni)haaramist, sks begreifen, rts begripa, pr comprendre 'aru saama, mõistma' < ld comprehendere 'kinni haarama, kinni võtma, kinni püüdma'. 


\title{
5. Intellektuaalsete võimete rollid mälu protsessides ja seisundites
}

Kõigi mälu protsesside ja seisundite asukohaks on intellektuaalsed võimed mahutina. INFORMATSIOONI meeldejäämine esineb jäämise (57) või settimisena (58) mahutisse.

（57） Need read jäid mulle igaveseks pähe. (Eesti_Ekspress_1998)

(58) Teinekord kokkusaamist otsitakse, ja ikka kindla pilguga, valmisolekuga märgata seda, mis kunagi on juba teadvusse settinud --- (Google; arhiiv2.postimees.ee8080)

\author{
INFORMATSIOON ON AINE \\ INTELLEKTUAALNE VÕIME ON MAHUTI \\ MEELDEJÄÄMINE ON AINE MAHUTISSE JÄÄMINE
}

Meeldejäämisel püüab informatsioon sisenedes pääseda võimalikult sügavamale, võtta mahuti sees kindlamat ja stabiilsemat positsiooni. Selleks, et võtta mahutis kindlamat, püsivamat, stabiilsemat, tugevamat positsiooni, võib INFORMATSIOON käituda sisenemisel üsnagi agressiivselt - tungida nagu nael tungib terava otsaga ihu sisse (59), ajada juured alla, hiilida võimalikult sügavamale põhja, imenduda (60-62). INFORMATSIOONI võib sisestada mahutisse - jätta (63), panna hoiule (64) hoidmise eesmärgiga.

(59) Päeva jooksul kuuldud kõnedest olid talle kõige teravamini meelde lõikunud Madjaku sõnad ---. (ILU1930 \ramoo42)

(6o) Tundsin tüdruku kohe ära, tema pilt oli mulle eriliselt meelde sööbinud. (SEGAILUOO40)

(61) Sõnad on talle ammu pähe kulunud ---. (Eesti_Ekspress_1997)

(62) Üks mittemõistmise juhtum on mul eriti jäävalt hallollusesse süüvinud. (SEGAILUO100)

(63) Ta vaatas tähelepanelikult toas ringi, tahtis täpselt meelde jätta, kuidas üks või teine asi seisab, et siis oleks pärast selge, mida ma segi ajanud olen. (SEGAILU/oo18)

(64) Ja mina mäletan kõike nii, nagu oleksin selle momendi fotografeerinud ja pildi ajudesse hoiule pannud. (ILU1980 \stktoo91)

\author{
INFORMATSIOON ON AINE \\ INTELLEKTUAALNE VÕIME ON MAHUTI \\ MEELDEJÄTMINE ON INIMESE POOLT AINE MAHUTISSE JÄTMINE
}

Kui INFORMATSIOON viibib peas ja meeles staatilises olekus, väljendab see INFORMATSIOONI hoiul olekut ehk mäletamist ${ }^{3}$ :

(65) Puusepal on väga kehv nimemälu, meeles seisavad ainult üksikute tuttavate nimed. (Eesti_Ekspress_2001)

\footnotetext{
3 INFORMATSIOONI staatiline olek väljendab mäletamist ainult pea ja meele mahutite puhul. Olenevalt lause sisust võib peas staatilises olekus viibiv INFORMATsIoon väljendada ka intensiivset mõtlemist, nt lause (37).
} 
INFORMATSIOON ON AINE

INTELLEKTUAALNE VÕIME ON MAHUTI

MÄLETAMINE ON AINE (HOIUL) OLEK MAHUTI SEES

Mäletamine esineb ka inimesepoolse sihikindla hoidmisena: et väärtuslik vajalik INFORMATSIOON ei lahkuks mahutist, tuleb see mahutis säilitada - pidada (66) ja hoida (67).

(66) --- ta suudab korraga meeles pidada kümne partii seise ilma lauale vaatamata. (Eesti_Ekspress_2001)

(67) hommikust saadik juba meeles hoidnud ja teistele meelde tuletanud, et täna Aadu muldasängitamise päev. (ILU1990 \ilu0510)

\author{
INFORMATSIOON ON AINE \\ INTELLEKTUAALNE VÕIME ON MAHUTI \\ MÄLETAMINE ON AINE INIMESEPOOLNE HOIDMINE MAHUTIS
}

Jäkel (1995: 214) kirjeldab meenutamist/meenumist (ingl remembering) kui "teadmisüksuste tagasitoomist mälu laost mentaalsesse töökotta”. Kui INFORMATSIOON tõuseb mahuti seest, mahuti põhjast (68-69), siis tegu on mahutis olemasoleva INFORMATSIOONI aktiviseerumise ehk meenumisega:

(68) Konkurentsitult tõuseb meelde Tobias George Smolletti kelmiromaani "Roderick Randomi seiklused" tõlge ---. (Postimees_1996)

(69) Ainult ajus tõusevad sisepildid minevikust ---. (ILU1980 \stkto054)

\author{
INFORMATSIOON ON AINE \\ INTELLEKTUAALNE VÕIME ON MAHUTI \\ MEENUMINE ON AINE MAHUTIS TÕUSMINE
}

Meenutades liigutab inimene mahutis hoiul olevat INFORMATSIOONI. Liigutamine võib esineda keerutamise (70) kujul.

(70) Juba praegu, veel enne, kui see seiklus siin minevikuks on saanud, hakkab nostalgia vaikselt hinge pugema, keerutades peas mälestusi ---. (Google; katutsehhis.blogspot.com)

\author{
INFORMATSIOON ON AINE \\ INTELLEKTUAALNE VÕIME ON MAHUTI \\ MEENUTAMINE ON AINE INIMESE POOLT LIIGUTAMINE MAHUTIS
}

INFORMATSIOONI liigutamine omab sarnaseid jooni mõtlemise ja kujutlusega (71). Mälus ja kujutluses võib inimene taastada seda, mida ta on näinud, tunnetanud, tajunud. Mälu erineb mõtlemisest ja kujutlusest INFORMATsiooni sisu poolest: mälu INFORMATSIOON jääb tervikuna minevikku, mõtlemise ja kujutluse INFORMATSIOON ei seostu ainult mineviku, vaid ka oleviku ja tulevikuga. Mõtlemise tihedat seost teadmise, kujutluse, usu ja mäletamisega mainib Michael Fortescue (2001: 17) mentaalse tegevuse naiivteooria ühe põhjapaneva komponendina: "When you think, you do so about what you know or imagine, or believe to be the case, or what you remember or intend doing ---”. Ununemist väljendab INFORMATSIOONI lahkumine mahutist (72). 
(71) olen sageli avastanud end juba trükivalmis lausetes mõtlemast, keerutades peas sõnu, mida võiks mu järgmisesse blogiposti kirjutada (Google; www.ekspress.ee)

(72) --- nimede peale on mul üldse sant mälu, nende peale ma mihkel ei ole, kaovad kohe meelest. (ILU1990/ilu0275)

\author{
INFORMATSIOON ON AINE \\ INTELLEKTUAALNE VÕIME ON MAHUTI \\ UNUNEMINE ON AINE LAHKUMINE MAHUTIST
}

Inimene võib proovida (kas ise või millegi vahendusel, kellegi abil) tüütust INFoRMATSIOONIST lahti saada - unustada või loobuda mõtlemast, mäletamast (73-74), kuid INFORMATSIOONIST lahtisaamine ei pruugi alluda inimese tahtele (75).

(73) "Enamik noori ja veel kogenematuid suusahüppajaid suudavad kõik ebameeldiva peast välja heita," ---. (Postimees_1997)

(74) Vahel osutub raskeks vabastada aju muude murede kütkest ja keskenduda õppusele. (TEA1980 \tttoo53)

(75) Üks selline sõlm oli seal ka, mis üldse enam peast välja ei lähe. (Postimees_1997)

INFORMATSIOON ON AINE

INTELLEKTUAALNE VÕIME ON MAHUTI

UNUSTAMINE ON MAHUTI INIMESE POOLT VABASTAMINE AINEST

\title{
6. Intellektuaalsed võimed eesti keele maailmapildis: tegija, mahuti, instrument, ruum
}

Jäkeli (1995) inglise keele andmete põhjal üles ehitatud mudel Mental activity is manipulation esitab mentaalset tegevust kui inimese poolt sooritatavat objektide käsitsemist, mille puhul intellektuaalsed võimed esinevad kas instrumendi või töökojana. Siin analüüsitud sõnade kasutused näitavad, et eesti keele maailmapildis ei piirdu intellektuaalsete võimete esinemine üksnes töökoja või inimese poolt kasutatava (käsitsetava) tööriista rolliga. Eesti keele maailmapildis esinevad intellektuaalsed võimed neljas rollis: tegija, mahuti, instrumendi ja ruumina.

Tegijana tegutsevad intellektuaalsed võimed sooritavad intellektuaalset tegevust iseseisvalt, ilma inimese vahenduseta. Tegijana figureerivad intellektuaalsed võimed mõtlemisel (INFORMATsIOONI töötlemisel ja tootmisel) ja mõistmisel (INFORMATSIOONI vastuvõtmisel). Tegija rollis sooritavad intellektuaalsed võimed ainult mentaalsesse maailmapilti kuuluvaid tegevusi, s.t nii neid, mis kuuluvad intellektuaalsfääri, kui ka neid, mis hõlmavad emotsioone, soove, kõnet.

Mahutina täidavad intellektuaalsed võimed väga tähtsat rolli mõtlemisel ja mõistmisel, aga eriti mälu protsesside ja seisundite puhul, kus mahuti on meeldejäämise ja -jätmise, mäletamise, meenu(ta)mise, ununemise ja unustamise asukoht.

Instrument ja ruum on kaks viisi, kuidas inimene kasutab oma intellektuaalseid võimeid. Instrumendina rakendab inimene intellektuaalseid võimeid mingi 
tegevuse sooritamiseks tööriista, vahendina. Instrumendina kasutatakse intellektuaalseid võimeid mõtlemisel (INFORMATSIOONı töötlemisel) ja mõistmisel (INFORMATSIOONI haaramisel). Instrumendi rolli abil sooritab inimene nii mentaalsesse maailmapilti kuuluvaid tegevusi (sh teadmist, mõtlemist, mõistmist) kui ka tegevusi, mis ei kuulu mentaalsesse maailmapilti (nt tegevusi, mille eesmärgiks on materiaalse heaolu saavutamine, materiaalsete hüvede teenimine ja suurendamine).

Ruumina kasutatakse intellektuaalseid võimeid mõtlemisel (INFORMATsIoonI töötlemisel), viibides intellektuaalsete võimete sees. Intellektuaalsete võimete sees võib inimene tajuda, nt näha ja kuulda (selles kontekstis pole tüüpiline intellektuaalsete võimete instrumendina kasutamine), teada, mõelda ja mõista, sooritada arvutamist, rehkendamist, lugemist, kirjutamist.

\section{Kokkuvõtteks}

Artiklis üles ehitatud metafoorid näitavad eesti keele maailmapildis peituvaid naiivseid teadmisi ja ettekujutusi inimese intellektist. Intellektuaalseid võimeid tähistavate sõnade kasutuste analüüs näitas, et intellektuaalsed võimed esinevad eesti keele maailmapildis tegija, mahuti, instrumendi või ruumi rollides.

Mõtlemisel esinevad intellektuaalsed võimed kõigis neljas rollis: tegija, instrumendi ja ruumi roll toimib INFORMATSIOONI töötlemisel ja tootmisel; mahutina toimub mõtlemine kui INFORMATSIOONI liikumine või muut(u)mine.

Mõistmisel esinevad intellektuaalsed võimed kolmes rollis: tegijana, kes võtab INFORMATSIOONI vastu; instrumendina, mille abil inimene haarab INFORMATSIOONI ja mahutina, kuhu INFORMATSIOON jõuab.

Kõigi mälu protsesside ja seisundite asukohaks on intellektuaalsed võimed mahutina. Kõik mälu protsessid ja seisundid moodustavad kontseptuaalsete metafooride paari, kus ühes metafooris on tegija INFORMATsIOON ja teises inimene: meeldejäämine (INFORMATSIOONI jäämine mahutisse) ja meeldejätmine (inimene sisestab INFORMATSIOONI mahutisse); meenumine (INFORMATSIOONI mahuti põhjast/ seest tulek), meenutamine (inimene liigutab INFORMATSIOONI); mäletamine (INFORMATSIOONI mahuti sees hoiul olek ning see, et inimene hoiab INFORMATSIOONI mahuti sees); ununemine (INFORMATSIOONI lahkumine mahutist) ja unustamine (inimene vabastab end INFORMATSIOONIST).

\section{Viidatud kirjandus}

Apresjan 1995 = Апресян, Ю. Д. 1995. Избранные труды. Том II. Интегральное описание языка и системная лексикография. Москва: Школа “Языки Русской Культуры”.

D’Andrade, Roy 1987. A folk model of the mind. - Dorothy Holland, Naomi Quinn (Eds.). Cultural Models of Language and Thought. London: Cambridge University Press, 112-148.

D’Andrade, Roy 1995. The Development of Cognitive Anthropology. Cambridge: Cambridge University Press.

Fortescue, Michael 2001. Thoughts about thought. - Cognitive Linguistics, 12 (1), 15-45. doi:10.1515/cogl.12.1.15

Jäkel, Olaf 1995. The metaphorical concept of mind: "Mental activity is manipulation". John R. Taylor, Robert E. MacLaury (Eds.). Language and the Cognitive Construal 
of the World. Trends in Linguistics. Studies and Monographs, 82. Berlin, New York: Mouton de Gruyter, 197-229.

Lakoff, George 1980. Women, Fire and Dangerous Things: What Categories Reveal about the Mind. Chicago, London: University of Chicago Press.

Lakoff, George; Johnson, Mark 1999. Philosophy in the Flesh. The Embodied Mind and its Challenge to Western Thought. New York: Basic Books.

Metslang, Helle 2002. Grammatikalisatsiooniteooriast eesti keele taustal. - Renate Pajusalu, Ilona Tragel, Tiit Hennoste, Haldur Õim (toim.). Teoreetiline keeleteadus Eestis. Tartu Ülikooli üldkeeleteaduse õppetooli toimetised, 4. Tartu: Tartu Ülikooli Kirjastus, 164-178.

Vakk, Feliks 1970. Suured ninad murdsid päid ... (Pea ja selle osad rahvalike ütluste peeglis). Tallinn: Valgus.

\footnotetext{
Allikad

EKSS $=$ Eesti kirjakeele seletussõnaraamat. Köited I-IV. 1988-2005. Tallinn: Eesti Keele Instituut.

Google = Google. http://www.google.ee (05.03.2009).

TÜKK = Eesti Kirjakeele Korpus 1980-1990.http://www.cl.ut.ee/korpused/kasutajaliides (05.03.2009).
}

Larissa Degeli (Narva Linnavalitsuse kultuuriosakond) peamised uurimisvaldkonnad on leksikaalne semantika, kõrvutav keeleteadus.

larissa.degel@narva.ee 


\section{THE CONCEPTUAL ROLES OF INTELLECTUAL ABILITIES IN THE WORLDVIEW OF ESTONIAN}

\section{Larissa Degel}

Narva City Administration, Culture Department

This research focuses on the meaning of the linguistic expressions of intellectual abilities in Estonian that are related to the activities of thinking, understanding and the use of memory. Through this the paper analyzes the worldview reflected in these instances of use. A suitable descriptive tool for analyzing these roles is conceptual metaphors. The aim of the research was to construct conceptual metaphors of the expressions of thinking, understanding and using memory through the notion of intellectual ability. The analysis is based on the Corpus of Written Estonian and the material of Google search.

In the worldview of Estonian an intellectual ability is usually depicted as 1) an agent (a worker), 2) a container of intellectual processes or states, or as 3) an instrument which is used by a person, or 4) a room where a person carries out an intellectual activity. When talking about thinking the intellectual abilities were described by all of the above mentioned roles. When talking about the intellectual abilities in relation to understanding the roles of container, worker and instrument were used. When talking about memory the intellectual abilities were described only by the container of intellectual processes and states metaphor.

Keywords: mental worldview, intellectual shpere, folk theory, conceptual metaphors, Estonian 